\title{
Erratum to: Management of Fat Accumulation in Patients with HIV Infection
}

\author{
Julian Falutz
}

Published online: 27 September 2011

(C) Springer Science+Business Media, LLC 2011

Erratum to: Curr HIV/AIDS Rep (2011) 8:200-208

DOI 10.1007/s11904-011-0087-3

The original version of this article contained errors in Table 1 and Table 2. The data in the Arm 1, Arm 2, and Arm 3 columns of the tables were incorrectly aligned. The correct tables are presented here.

The online version of the original article can be found at http://dx.doi. org/10.1007/s11904-011-0087-3.

J. Falutz $(\bowtie)$

Immunodeficiency Treatment Center,

McGill University Health Center,

Room A5-140 1650 Cedar Avenue Montreal,

Quebec, Canada H3G 1A4

e-mail: julian.falutz@muhc.mcgill.ca 


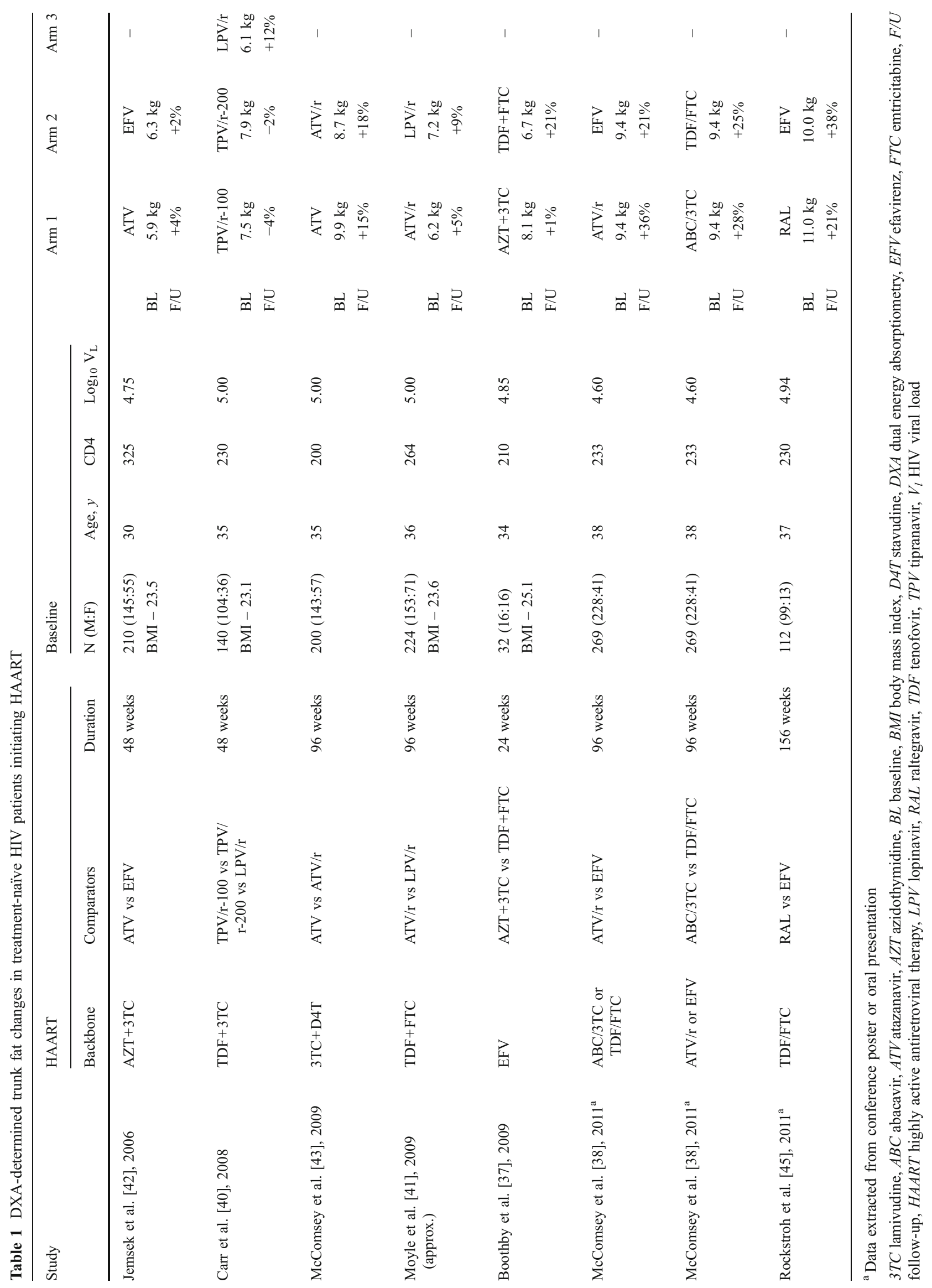




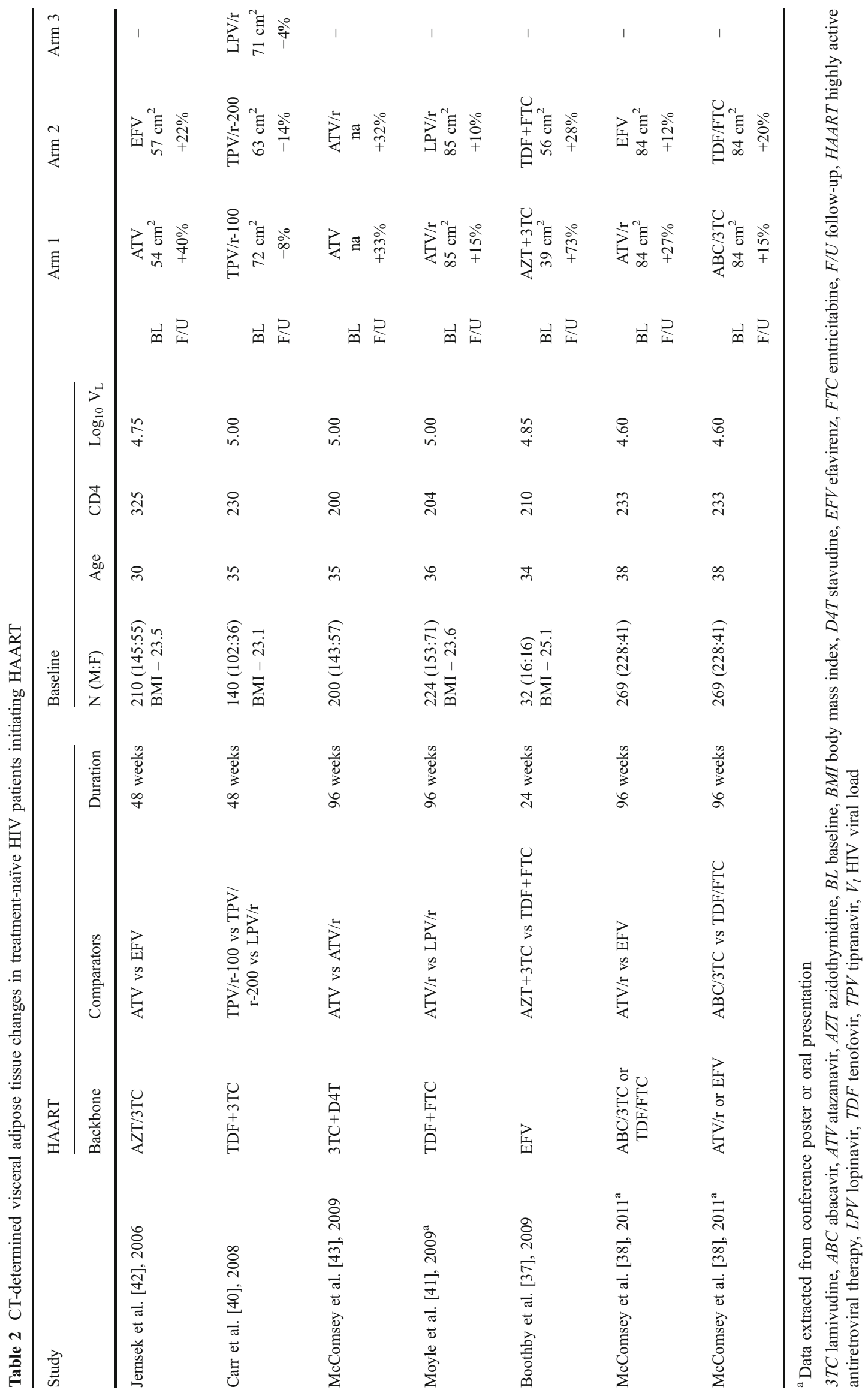

